\title{
Representación del Pachakutiy en la poesía de César Guardia Mayorga
}

IRepresentation of Pachakutiy in the poetry of César Guardia Mayorga

\author{
Mauro Mamani Macedo \\ Universidad San Ignacio de Loyola \\ Universidad Nacional Mayor de San Marcos \\ Contacto: mauro.mamani@usil.pe
}

\begin{abstract}
Resumen
La colonización epistémica consiste en imponer a una comunidad cultural un conjunto categorial extranjero, ajeno y distante. Esta actitud desconoce las formas de pensar, clasificar y sentir de la cultura nativa en la cual se ejerce su poder categorial. Frente a ello, consideramos que cada cultura tiene sus palabras, su diccionario, su enciclopedia, su qipi teórico para organizar su conocimiento. En este artículo estudiamos la categoría andina del Pachakutiy, además verificamos su alcance teórico y hermenéutico en la interpretación. Organizamos nuestro artículo en dos partes. Primero, desarrollamos una indagación filológica del concepto pachakutiy. Segundo, aplicamos esta categoría en la poesía de César Guardia Mayorga con la finalidad de demostrar su capacidad descriptiva y analítica mediante la visibilización de la alternancia de los tiempos.
\end{abstract}

Palabras clave: Pachakutiy, Poesía quechua, Arguedas, Kilku Warak'a, Guardia Mayorga

\begin{abstract}
The epistemic colonization implies the imposition of foreign categories, which are external and distant. In other words, this action does not recognize the native culture and its forms of comprehension, classification and sensation. For this reason, we affirm that any culture has its words, its dictionary, its enciclopedia, its theoretical qipi to organize its knowledge. In this paper, we will study Pachakutiy, an Andean category; moreover we will verify its theoretical and hermeneutic scope in the literary interpretation. Firstly, we will propose a philological revision of the concept Pachakutiy. Secondly, we will use this category to analyze the poetry of César Guardia Mayorga. In this way, the visibilization of the alternation of times in his literary work will demonstrate the Pachakutiy's descriptive and analytic capacity
\end{abstract}

Key words: Pachakutiy, Quechua Poetry, Arguedas, Kilku Warak'a, 
Guardia Mayorga

Recibido: 03.10.16

Aceptado: 14.05 .17

\section{Pachakutiy: vuelta del tiempo-mundo}

La categoría pachakutiy se compone de dos conceptos: Pacha ${ }^{1}$ y kuti. La primera significa el tiempo y el espacio, tal como registra González Holguín "Pacha. Tiempo suelo lugar" (1989, p. 268); mientras que la segunda representa los cambios, los trastornos o las vueltas, desde las más complejas como voltear el mundo hasta las más sencillas como responder una pregunta, así lo explican las siguientes palabras "Cutini. Boluer alla otra vez; Cutimuni Boluer aca el que se fue; cutipuni, Boluer alla otra vez" (González Holguín, 1989, p. 57). En tal sentido, el kuti es entendido como una alternancia de contrarios, porque esas dos cosas no pueden andar juntas, una está en un bando y la otra se ubica al frente; esta permutación es el kuti, el turno, el cambio, la vuelta. Al fusionar los dos significados encontramos la explicación de la representación del turno de un tiempo y el consecuente paso a otro tiempo. Por ejemplo, el cambio de un tierra que está en la superficie y va hacia el fondo; y la que estaba al fondo se muestra al sol, este mecanismo se observa en el mundo agrícola mediante el barbecho, cuya finalidad es oxigenar la tierra, removerla para renovarla. De esta forma se prepara para que pueda rendir mejores frutos. A mayores escalas, el pachakutiy es el cambio del tiempo-mundo. Esta misma idea de alternancia se puede observar en la palabra Vilcacuti:

[...] vuelta del sol [...] que divide el año en dos, el ciclo solar se invierte: a un sol que crece diariamente de julio a diciembre se opone un sol menguante de enero a junio, se dice que el sol cumple una revolución durante el solsticio. Es como 'volverse dentro' (cutintatha) o 'destorcer lo torcido' (cutiquipaata). (Harris y Bouysse-Cassagne, 1988, p. 243)

Ello involucra un cambio de tiempo atmosférico con todas las consecuencias que arrastra esta permuta, como las siembras y las cosecha; como los fríos y los calores; como los tiempos de fiestas y danzas, y un tiempo de aflicción y llanto. 
El pachakutiy es una de las categorías andinas más difundidas y de mayor éxito en la explicación de los fenómenos culturales y en las representaciones literarias. Pachakutiy significa la imagen del mundo al revés y se refiere a un "cataclismo cósmico"; así, "se usaba para designar el tránsito de una edad a la otra dentro de un esquema temporal de cinco edades míticas" (Ossio, 2008, p. 220). Precisa Ossio que "Etimológicamente, este término significa 'el mundo se transforma' (Pacha $=$ mundo y cuti $=$ se transforma) y en los vocabularios y gramáticas de la lengua quechua generalmente es traducido como 'fin del mundo"' (Ossio, 2008, p. 221). En efecto, Diego González Holguín registra que "Pacha cuti pacha ticra. El fin del mundo, o grande destrucción pestilencia, ruyna, o pérdida, o daño común” (1989, p. 270). Se puede advertir entonces distintos grados, pero que son significativos, el "daño común” —es decir, no es privativo o individual sino involucra a varias personas-, es un tiempo en el que reina la desintegración, ya sea física o moral. Por ejemplo, la "pestilencia”, que vinculada a los procesos de enfermedad y daño afecta en forma significativa porque produce pérdidas individuales que pueden extenderse a grandes colectividades; pero en el nivel más extremo significa el fin del mundo, un mundo enfermo, dañado, que se desintegra en forma violenta. Este fin del mundo es la muerte de un tiempo-mundo, el cierre de una época para el surgimiento de otra; es decir, muere un mundo para nacer otro, ya sea un nuevo mundo de lamento o de alegría. Pachakutiy es "lo que puede dar un vuelco total, es todo un mundo, toda una era, un pacha” (Harris y Bouysse-Cassagne 1988, p. 244): tiempo y mundo se trastocan.

En el Arte y vocabulario de la lengua general del Perú llamada quichua, y en la lengua española, publicado en 1586 en Lima por Antonio Ricardo, a la entrada de pachacuti le corresponde como referente 'fin del mundo'; el sustantivo pacha significa tierra/tiempo y el verbo kuti volver o voltearse" (López-Baralt, 2005, p. 329).

En la lengua aymara, Ludovico Bertonio registra: "Pachacuti. Tiempo de guerra. + Y también ahora lo toman para significar el juyzio final” (2006, p. 627). 
En principio representa un estado de crisis, de tensiones y enfrentamientos, que en el ámbito social son necesarios para los procesos de regulación; pero también puede generar cambios de mayor grado como la pérdida o sometimiento, lo que implica un cambio de tiempo, "ya no es nuestro tiempo", es "el tiempo de otros". Esta conceptualización se plantea desde una óptica con inclusión occidental, pues se representa como el juicio final bíblico, el castigo de los dioses que ven como intolerable las acciones de los hombres y deciden los cambios drásticos. En ese sentido se observa como una sanción.

En el ámbito de la naturaleza, se refiere a los trastornos que se dan en ella: los cataclismos, las erupciones volcánicas. Los volcanes, como los puquios, tenían vínculo y comunicación con los dioses, lo que entra en diálogo con las tres pachas. Así, los dioses del Uku pacha, los que estaban debajo de la tierra, y los del Hanan pacha se comunicaban; además, los mensajes confluyen en el Kay pacha o el mundo de acá, el de los vivos. Por ello, la erupción del Huayna Putina en el año 1600, "fue considerada por los indios de la región como una venganza de las antiguas divinidades contra los españoles, que podían trastornar el orden social” (Bouysse Cassagne 1987). Este hecho, por ejemplo, es un pachacutiy, una respuesta de los dioses por un tiempo trastornado, donde los hombres son humillados por el sometimiento que ejercen los falsos wiraquchakuna.

En este pachakutiy están presentes el fuego y la lluvia severa. El primero causa una devastación y está orientado a las erupciones volcánicas; el segundo origina las inundaciones. En ambos casos producen gran mortandad, mucha muerte entre hombres y los demás seres. González Holguín registra estos estados "Nina pachacuti. El fin del mundo por el fuego. Llocllauno pachacuti. Por el diluvio" (1989, p. 270); el fuego y el agua son instrumentos del pachakutiy, se puede quemar todo para que vuelva a brotar o se puede inundar todo para que germine nuevamente. Estas desapariciones y renovaciones se representan en forma insistente en Dioses y hombres de Huarochirí (Arguedas, 2007).

En el ámbito religioso, el pachacutiy también está vinculado al castigo divino; por ello, los cristianos utilizaron este término para traducir el Juicio Final. 
Guaman Poma registra el pachakutiy de la siguiente forma:

También había muy muchos milagros en este reino entre los indios que no dan fe en tiempo pasado, y de estos dichos ingas dicen que los pobres hermitaños y los flaires franciscanos pobres que los enviaba Dios para tentarles y para saber si tenían caridad con sus prójimos, de esto no dieron fe porque no había quién los escribiera, sino que dice que enviaba Dios en figura de flaire pobre y esto lo dicen, que pedía limosna por Dios, que le decían que le diera de comer y de beber, y entraban estos pobres grandes que hacían fiestas y taquies, y si no les daban limosna dicen que les castigaba Dios por ruego de ellos, les quemaba con fuego del cielo y en partes les cubrían los cerros y se hacían lagunas los dichos pueblos y les tragaba la tierra como fue el gran castigo de Dios en el mundo. Y los dichos milagros desde el principio. [...] Y así ha habido otros muy muchos milagros y castigos en el tiempo del Inga, no se escribe, sino son los testigos de la caída de los cerros y peñas derrumbadas, y así se escribe toda suma, por eso el castigo de Dios se llama pachacuti-pacha-tierra- y así algunos reyes fueron llamados Pachacuti, y en esta vida como hemos visto al reventar los volcanes y llover fuego del infierno y arena solar una ciudad y su comarca, y también se dice milagro el temblor de la tierra y morir mucha gente [...]. (Guaman Poma de Ayala, 1993, p. 74)

Ello se expresa como un castigo divino por las faltas que se han cometido en la vida. En este caso, Guaman Poma une el Pachakutiy cósmico con la dimensión divina. Esta transformación puede ser ejecutada por los reyes (Inca), por los que tienen la capacidad de cambiar grandes estados mediante la ampliación del territorio, como es el caso de uno de los Incas que tiene por nombre Pachakuteq ${ }^{2}$, el que cambia el mundo; en efecto, fue quien renovó el Tawantinsuyu.

En el campo religioso se puede observar un pachakutiy, pues los dioses que reinaban, son desconocidos, perseguidos y destruidos para imponerse otros dioses; así, las wakas pierden poder frente a los nuevos dioses. Una de esas manifestaciones que responden a este trastorno es el taki onqoy, la danza de la enfermedad, que se presenta precisamente por la desobediencia a los dioses nativos. Por esta razón, las wakas entran como una fuerza en dispersión a los cuerpos de los runakuna y los enloquece. 
Pachakutiy es la representación de los acontecimientos que dan vuelta a un tiempo, a una era, a un reinado. "Cuando un inka muere, se produce un pacha kuti. Cuando los españoles llegaron a los Andes se produce otro pacha kuti. En todos los casos se acaba una época del tiempo, un ciclo temporal" (Harris y Bouysse-Cassagne, 1988, p. 244). Un concepto vinculante es pacha ticra: aquel que pone la cabeza al revés; es decir, invertir las posiciones, pues si antes los pies estaban en la tierra, ahora está patas arriba: vale decir, poner al mundo de cabeza, el mundo al revés, tal como ocurrió con la llegada de los españoles. Así, puede ser definido el pachakutiy con la presencia funesta y engañosa de los españoles, que estropean y saquean una cultura, pero a su vez esta cultura tiene la oportunidad de voltear el tiempo. Con estas dinámicas es representado el pachakutiy en el poema “iHatarychik!” (iLevántense!) de Guardia Mayorga (2004, pp. 62-70).

En el ámbito social, está vinculado con el tiempo de las guerras o aucapacha, aquello que transforma la organización de los espacios sociales como resultado de enfrentamientos para ampliar su territorio, lo que traía como consecuencia un reacomodo cultural y social. Un pachakutiy en este sentido está representado por las guerras civiles entre los incas (Huáscar y Atahualpa), otro es el enfrentamiento que tuvieron los indígenas con los españoles, desde entonces se está gestando un nuevo pachakutiy para que el dolor que instalaron los españoles sea destruido (ñut'uy: molido, desmenuzado, pulverizado); es decir, espantar el mal tiempo para el retorno del mundo runa, esta idea se vincula con el mito del Inkarry, el inca desmembrado que se recompone debajo de la tierra ( $u k h u$ pacha) para volver a este mundo (kay pacha). Así, en la medida que es un evento simbólico compromete cambios culturales y sociales.

En la gestación de un pachakutiy entran en acción diversos actores como las plantas los animales, los dioses y los hombres. Dentro de la dimensión humana existen dos grandes actores que se van aspectualizando con el tiempo. Por un lado, están los que sufrieron los tremendos procesos de desintegración cultural: los runakuna; por otro, los que estaban asociados a los males: los falsos wiraquchakuna. El runa es una categoría central en la identidad y en la 
identificación que recibieron los hombres de estas tierras. Ellos son vistos como los allin sunquy, los hombres de buen corazón, que despliegan una vida de integración y solidaridad, aunque para la visión de los foráneos fueron vistos como unos salvajes, seres sin alma.

Los indios son ubicados en un estrato social de mayor marginación; por ello persiste la frase "inkas, sí; indios, no", en el sentido que solo se reconoce a los descendientes de un linaje imperial, pero no al inmenso pueblo que vive en las alturas, en la puna. Esta exclusión degradante muchas veces se opera desde los poderes académicos; por ejemplo, cuando no se le reconoce su saber y solo se da como cierto el saber "científico", cuando realmente existen varios tipos de saberes. Por ello, el reconocimiento de un solo tipo de saber se constituye en una forma de desprecio del conocimiento nativo y de sus formas de producirlo y reproducirlo ${ }^{3}$.

Campesino: este es un concepto más ideológico y está asociado con las luchas sociales. Es percibido como aquel que cultiva la tierra, pero también como el que tiene la capacidad de organizarse y sublevarse; así aparece representado tanto en los discursos sociales, culturales, literarios y en los significativos levantamientos campesinos cuando estos eran objeto de despojo por parte de los gamonales, hacendados o empresas transnacionales. Todo ello representa una continuidad con los levantamientos comunales anteriores.

Los Awqakuna son los grandes enemigos; los manan allin sunquy, los hombres de mal corazón; los runa mikuy, los que comen la fuerza de los hombres; los chiqni runa, los hombres de corazón aborrecible. Estos desde un inicio han sido vistos como falsos Wiraquchakuna. Es decir, se presentan como dioses pero no lo son, tal como se expresa en el poema de César Guardia Mayorga. Estos falsos wiquchakuna, en un primer momento, se encarnaban en los españoles, luego están representados por todos aquellos que oprimen al indio, como los gamonales, los patrones, los gringos y hasta los propios "indios mandoncillos".

En tal sentido, el awqa es lo que no puede ir junto. En un sentido moral o religioso, "Los evangelizadores utilizaron la palabra auca para oponer pecado a 
gracia y pachacuti para significar juicio final” (Harris y Bouysse-Cassagne, 1988, p. 244). La idea de los evangelizadores era concretar en esta palabra el significado del enemigo, incluso del enemigo de Dios; por ello eran Awqa todos aquellos que buscaban el mal, según sus intereses, cuando los verdaderos awqakuna son los amantes de las guerras porque se beneficiaban de este evento catastrófico, tal como se representa en el poema "Awqay" (La guerra) de César Guardia Mayorga (2004, pp. 72-73). Esta forma de mutilación semántica también se empleó con el término Supay (diablo), mediante el cual se produce un proceso de reducción porque solo se le asocia al mal cuando esta divinidad era dual, es decir estaba en el mal, pero también en el bien.

El Pachakutiy está representado en varias expresiones socioculturales: en la pintura, en la novela, en el cuento, en la tradición oral, en los huaynos, en las canciones pastoriles, en las llikllas. Por ejemplo, Manuel Scorza, en sus novelas, hace una representación de los cambios drásticos de la vida, donde las formas son alteradas, las ríos se detienen, los pájaros vuelan sin sentido, los meses ya no se corresponden con su nombre, esto como una forma expresar los dolorosos y trastornados tiempos que se vivían en la comunidades andinas, cuyos pobladores eran sistemáticamente despojados de sus tierras. En ellos se representa los grandes momentos de cambio, de transformación de la realidad, lo que configura un pachakutiy social; es decir, representa un cambio hacia lo malo o un cambio hacia lo bueno. Con este último significado, por ejemplo, se han leído los recientes cambios políticos de la sociedad boliviana ${ }^{4}$, donde las actitudes culturales positivas hacia lo indígena son favorables.

César Guardia Mayorga: “iHatariychik!”

César Guardia Mayorga o Kusi Pawkar (1906-1983), fue un hombre multifacético: poeta, maestro y filósofo. Dentro de sus obras se registran: Léxico filosófico (1941); Historia de la filosofía griega (1953); La reforma agraria en el Perú (1957); Psicología del hombre concreto (1967); y Filosofía, ciencia y religión (1970). En quechua ha publicado Diccionario kechwa-castellano (1959), Gramática Kechwa (1974) y su libro de poesía Runasimi Harawi (1975), en cuyos poemas se aprecia la 
diversidad de temas sobre los que ha reflexionado y escrito. Es amplio el universo temático que ha pensado César Guardia Mayorga: educación, linguíística, filosofía, psicología, literatura; en este último campo es donde más se ha descuidado la atención a su obra, no obstante, ya existe una investigación: "La pervivencia de la identidad cultural como memoria del tiempo moderno en Sonqup jaraviini, Humapa jamutaynin, Runap kutipakuynin de Kusi Paukar” (2017), tesis realizada por Óscar Huamán, joven investigador quechuablante, quien con un acercamiento desde el saber y sentir quechua indaga en la memoria de esta escritura.

Su libro Runasimi harawi (2004) $)^{5}$ reúne su poesía y está compuesto por tres partes. En la primera, “Sunqup harawiynin” (el cantar del corazón), el tema central es el amor; así el primer poema “Waylluy”, reflexiona sobre su naturaleza, describe la forma cambiante y extraña de presentarse, acercarse, alejarse y perderse. De estas cambiantes modulaciones, solo su corazón sabe: "Sunqullaymi yachan" (p. 8), como una memoria y un saber interior que asimila el tránsito de ternura y dolor en el hombre que ama. En el poema "Walka" se representa al amor nostálgico, sentimiento que se rememora para seguir existiendo, pero también socava la identidad representada en un nombre: Walka, que puede cambiar como cambia el amor; así, el hablante lírico se refiere desde la equivalencia entre warmi (mujer) y urpi (paloma), que son nombres más universales y fijos frente a Walka que es cambiante, de esta forma cambia el nombre, pero no la mujer. "Qampaq" representa al amor que no se puede borra de la memoria y que sufre con su recuerdo.

También está el poema de amor al pueblo que lo acogió, Arequipa "Arí, qipay", donde hace un recuento del tránsito de hombre y pueblo porque sus vidas corren trenzadas; este es pues su segundo pueblo: "iArequipa llaqta, / llaqtay ranti!" (p. 20). Lo hace recordar su pueblo mediante la conexión de sus apukuna representativos: "iHayka kutim / Misit urquykita qawaspa, / Sarasara urquyta/yuyarqani! (Cuántas veces / mirando a tu cerro, el Misti, / recordé a mi cerro, / el Sarasara” (pp. 22-23). También existen poemas a los cambios de tiempo 
como las estaciones y los años, así como a la sagrada hoja de coca, "Kuka Kintu”, con ella establece un sutil diálogo existencial acerca de la vida y del porvenir, de las predicciones y concretizaciones. En síntesis, es una sección dedicada a las relaciones sensibles, vínculos afectivos del hombre consigo mismo, con los semejantes, con la naturaleza, con los contextos y con los tiempos.

"Umapa hamutaynin" (El pensar de la mente), es un conjunto de poemas con aliento filosófico porque reflexionan sobre el ser, el mundo y los sucesos cotidianos en general. En esta segunda parte, por ejemplo, el primer poema "kay mana kay" (ser o no ser), reflexiona acerca de los dilemas existenciales del hombre que vinculan la fugacidad de la vida con los devenires incesantes de la muerte, configurando escenarios movedizos donde surgen preguntas sobre la identidad que no encuentran respuestas. En esa misma orientación se plantea el segundo poema, "Kay”( ser); aquí las pulsiones se establecen entre el ser y la nada, confrontaciones de donde surge la naturaleza del ser y el existir del hombre. A todo ello se suma la pregunta, la verdad, la duda y lo indetenible en este mundo: "Kay pachapiqa / manam imapas qasilla kanchu, / manam imapas samanchu" (En este mundo / no hay nada tranquilo, / nada descansa” (pp. 50-51), todo está en ferviente dinamismo, en pleno kawsay, con un total vitalismo energético.

La tercera parte, "Runap kutipakuynin” (La respuesta de la gente), está compuesta de poemas con motivo sociocultural, ya que representan las luchas que emprenden los hombres para lograr la justicia, tanto en lo cultural (respeto a los usos, costumbres y cosmovisión nativa), como en lo social (una búsqueda de mejores condiciones de vida). "Runap kutipakuynin” está compuesta de cuatro poemas: "Chiqapllan" (Es la verdad), "Puka llaqtapaq" (Para el pueblo rojo), “iHatariychik!” (iLevántense!), “Awqay” (la guerra), a ello se suma una prosa "Mayupata qawanamanta” (Del mirador del río). Estudiaremos esta sección y en especial el poema "Hatariychik". En los cuatro poemas se expresa una denuncia sociocultural por las condiciones deplorables en que viven los runakuna, quienes perdieron su condición de dueños de estas tierras andinas y son sometidos por 
un poder inclemente. La prosa poética, que está al final de esta sección, muestra una actitud melancólica con respecto al paso del tiempo, pero desde ese recuerdo surge una decisión de avanzar.

En la estructura y distribución de las secciones se advierte una secuencia. Primero un corazón que canta, luego una cabeza que piensa, finalmente un cuerpo colectivo que responde. Las tres partes se correlacionan: sentir, pensar y responder. La respuesta implica una acción que es producto de la confluencia de los dos estados anteriores en los cuales se añora un cambio o una nostalgia por la luz, por el amanecer.

En la primera sección del corazón, del canto y del sentir se pueden apreciar estos versos, que representan un kutiy inesperado: "Kusi tutapi, / kuyanakuqkuna tantanakuptin, / tutapas sunqu kaytam munan, / waqaypas asiykayta munan, / llakipas chisiyan, / kusipas achikyan (En la noche alegre, / cuando se reúnen los que se quieren, / La Noche quiere también tener corazón; / el llanto quiere convertirse en risa, / la pena anochece, / amanece la alegría) (pp. 32-33). Este gran amor contagia a la noche, por ello se despoja de su manto negro, quiere cantar y bailar, quiere tener corazón y amar. Este amanecer de alegría puede ser permanente si se juntan en un intenso grito colectivo. "Kayna wiñay kanampaq, / qaparispa haylliykusun, / qamakunarayku,/ñuqaqchik rayku, / llapan rayku, / iHaylli! iHaylli!" (Para que así sea siempre, / gritemos con emoción:/ por ustedes, / por nosotros, / para todos, / ijaylli! ijaylli!) (pp. 32-33), ijaylli!, es el grito de triunfo en las guerras o en las celebraciones o cuando se derrota el llanto, la pena y la noche, porque esta tremenda alegría provoca cambios drásticos como el inusitado deseo del llanto de ser risa.

Esta es una forma de pachakutiy, aquí no es un hombre o una mujer que pasa de la pena a la alegría, sino es una profunda transformación porque es el propio llanto el que quiere ser risa. En tal sentido es una remoción ontológica, lo abstracto se concretiza, toma formas antropomórficas y experimenta emociones, una doble transformación, que puede interpretarse en niveles de profundidad, como cuando lo degradado, lo oscuro, lo tenebroso reniega y 
abandona su negativa identidad para asumir otra, por ejemplo, el resplandor; así se pasa del tutay tutay al K'anchariy k'anchariy, de la prieta oscuridad al máximo fulgor. Considerando que este evento es simbólico debe representar dimensiones más vastas, por ello no queda en una individualidad.

En la sección del pensar (hamut'ay) también es potencial la idea de la transformación (kutiy). Así en el poema “ilmapaq!” (para qué), dedicado a su amigo Jesús Lara, poeta boliviano quechua, quien lo incluye en su libro $L a$ literatura de los quechuas. Ensayo y antología (s/f). En el poema se interroga sobre la razón de los tiempos y de los estados de ánimo debilitados por los que atraviesa una persona; estos estados se pueden transformar desde el latido del corazón: “¿Imapaqmi kumuykachay/ sunqu kawsachkaptinraq?” (Para qué andar cabizbajo / si aún late el corazón) (pp. 42-43), es decir, el corazón es capaz de sacudir los estados de ánimo, su vida expresada a través de sus palpitaciones puede poner el ritmo de lo que existe y ello se extiende al levantamiento físico y social. No vivir humillado, agachado, sino con la fuerza del sentimiento, erguirse, en una especie de sacudimiento y liberación de cierta opresión en el corazón, de esta forma la imagen subvertora alcanza lo social. Así, como el corazón extiende su potencial, la cabeza, el cerebro puede dispersar su poder para iniciar un kutiy: “ilmpaqmi kawsani?, / nispa, tapukuptiyki, / hamutayniyki nisunki, / sunquyki kutichinku / kay nispa: ikaruraqmi purina, / tukuyraqmi rurana, / mana samaspa llamkana, / aswaraqmi yachana, ancharaqmi waylluna, sinchiraqmi awqana! (Cuando te preguntas: ¿para qué vivo? / Protesta el corazón, / y el cerebro te dice: / — todavía hay que andar lejos / todo está por hacer/ trabajando sin descanso. / Mucho más aún que aprender, / mucho que amar, / muchísimo aún que luchar. /" (pp. 42-43). Aquí se juntan el corazón y la cabeza como impulsores, pero sobre todo se correlacionan tres verbos que conducen a un cambio: Waylluy, yachay, awqay (amar, aprender y guerrear).

Como puede apreciarse, en esta sección, dedicada al pensar, también está subyacente la idea del cambio, del kutiy, vuelta, retorno, y en esa vuelta está implícita la idea del pachakutiy, el cambio del tiempo-mundo. Sin embargo este 
no es un simple cambio, sino que involucra a la totalidad del cuerpo, pero también su relacionalidad, es decir, se integra al cuerpo colectivo, al universo social que palpita y piensa como el hombre. En tal sentido, una de las estrategias poéticas que sigue el enunciador es una convocatoria a la unidad, donde cabeza y corazón van juntos, en yanantin, en potente y amorosa unión ${ }^{6}$. No se admite lo desmembrado, sino una confluencia de fuerzas en la unidad; así demuestra la potencialidad de cada uno: del corazón y de la cabeza, para configurar una unidad fortalecida, pero no en una individualidad sino en una colectividad, por ello el grito es social, como en el poema "Katatay" de José María Arguedas "Huñunakuychik llaqtay, runa" (Formen una sola sombra, hombres, hombres de mi pueblo" (1984: pp. 36-37).

Esta idea acumulativa, secuencial, progresiva, se puede apreciar en la disposición de los poemas de la última sección; por ejemplo, “Chiqapllam”, da cuenta de la verdadera vida que pasan los hombres pobres, quienes tienen que trabajar y andar día y noche, estado que parece interminable porque se repite todos los años. Frente a esta vida deplorable, el enunciador se pregunta “¿Imanaykamapunitaq kaynalla kasaqku?” (¿hasta cuándo vamos a estar así?) (p. 54), es decir sin nada para los pobres, solo el estar abrumados por su sufrir, por su sudor, por su cansancio, viviendo en la pobreza; obviamente la pregunta formula un llamado a cambiar un estado insoportable.

Un recurso acertado en el poema es el uso de las voces onomatopéyicas, que se trasmiten a través del sonido de los pasos, del incesante andar, (chaq, chaq, chaq) y del dolor (ay, ay, ay); de esta forma acercan el incansable dolor de los hombres, mediante la proximidad fónica, porque se conecta más con la realidad, y esto enardece con sutileza, pero no desencadena. En este sentido, el poema plantea solo un estado carente, sin respuestas para cambiar, no avizora posibilidad de mudanza vital; aunque las preguntas orientan a un llamado a cambiar la situación, no obstante, en el desarrollo del poema no hay ninguna contestación.

"Puka llaqtapaq" (Para el pueblo rojo), en este poema se encuentran las 
respuestas que no estaban en el poema anterior; es como un poema secuencial, porque aquí sí hay una representación de un llamado explícito y una concretización por el cambio. Representa cómo se ejecuta el kutiy (transformación), pero también muestra las consecuencias que encamina. Todo ello lleva a la renovación de los escenarios de la vida, por ejemplo, la implantación del respeto y la felicidad, del libre cultivo de las tierras y del libre ingreso a las universidades. Todos estos cambios están impulsados por un reconocimiento de la sabiduría de nuestros antepasados. Por momentos el poema cae en una referencialidad, tratamiento que es más de orden ético que estético; por este tratamiento de lo representado se acerca al manifiesto directo antes que al trabajo estético, no obstante, el uso metafórico de los elementos de la naturaleza posibilita la construcción de un artefacto estético.

"Awqay" (La guerra), explora en los diversos significados de la guerra. Señala a quienes se benefician de las consecuencias de los actos calamitosos, por ejemplo, los poderosos aprovechan de estos eventos porque la crisis les permite acumular dinero, sin importarles el sufrimiento y muerte de los hombres, por esta razón adoran la guerra, la crisis. La codicia los enloquece porque conectan plata y poder ${ }^{7}$, una acumulación inexplicable para un runa, pero totalmente natural para un falso wiraqucha. "Paykunapaq / awqayqa, quri qullqitam apamun; / quiri qullqitam miraknin, / atipaytam qukun" (Para ellos, / la guerra trae plata, / aumenta el dinero, / da poder" (pp. 72-73); este es el estado hambriento de oro que viene desde la colina. También el poema explora el grado de hipocresía, es decir, predican el amor, cuando en realidad anidan odio en su corazón, esas formas simuladas perturban y engañan a los hombres. "¿Imaynataq uturunqu / urpituq turan kanman, / 'Panaymi' nitimpas? (¿Cómo puede el tigre / ser hermano de la paloma, / aunque diga: / 'Es mi hermana'?) (p. 72) lo que revela una imposibilidad de comunicación, de convivencia por falta de honestidad. En este sentido, para desaparecer la guerra, la crisis, se tiene que reconocer a los varaderos enemigos, porque existe un enmascaramiento de la identidad ya que la frase afectiva puede ocultar odio. 
En la prosa poética, que está al final de la sección, se pierde el carácter épico que existe en los poemas anteriores, pero gana en simbolismo. El carácter casi referencial que existía en los otros poemas disminuye. Contemplando a la naturaleza, reflexiona sobre la vida, actitud que lo conduce al pasado para alimentarse de su saber y recordar el sentido de su vida, porque es allí donde despiertan los recuerdos que lo hieren: "Chaypiña rikukuspataq, imaymana yuyariykuna rikutiyta qallaykun, sunquyta patpatichitin, hamutayniyta hamutachistin, ñuqa kikiyta nanachiwastin” (Al verme ahí me asaltaron los recuerdos haciendo palpitar el corazón, haciendo razonar a la razón e hiriéndome a mí mismo" (pp. 74-75), así "Mayupata qawanamanta” (Del mirador del río), es una prosa poética pensativa, donde se muestra el paso del tiempo, mediante la imagen del discurrir del río despliega la reflexión sobre la vida. Por ejemplo, observa cómo todo cambia en la existencia, entonces hay un pleno fluir. La naturaleza acompaña en la reflexión, así los vientos lo llevan al pasado, los ríos discurren como amaru, como el dios serpiente, el cóndor se vuelve tierno, revolotea en la choza y enamora, la calandria con su canto silencia a los otros pájaros; los árboles miran su rostro en los ríos que detienen sus aguas para jugar con sus ramas; también está la mosca que perturba y se ríe del hombre burlado y enojado, parece que todo ello lo retornara a la vida cotidiana, pero con otra decisión, pues su mirar no es de contemplación o interior, sino es una mirada de horizonte, de lejanía: "ñuqataq upallalla hatarispa, urqup qatanta siqayta qallaykuni humpistin, humpistin, hamutastin; karuniqta, karuniqta qawastin" (Y yo levantándome en silencio, como si me hubiese deshelado, empecé a ascender por la ladera verdosa del cerro, sudando, pesando y mirando en lejanía, en lejanía" (pp. 76-77), dos verbos dan cuenta de un cambio: hatariy, qallariy (levantarse y empezar), pero todo ello como resultado de su viaje al pasado, porque solo él cambia, porque la naturaleza sigue en su ferviente germinación de vida. De todas formas hay un antes y un después en la vida del hombre, ello tiene que ver con la grandeza porque empieza a ascender (siqay), y mirar la lejanía (karu), lo que implica el valor de su objetivo, no expresado, pero sí se puede 
inferir: kutiy, voltear.

El poema que mejor representa estos drásticos cambios temporales es "Hatariychik". Allí se simboliza los cambios que sufre la sociedad peruana en tres tiempos. Primero, se representa la vida armoniosa, el allín kawsay, el buen vivir, tanto entre hombres, como entre el hombre y la naturaleza. La segunda parte, representa la llegada de los falsos wiraquchakuna, lo que crea un estado de vida insoportable. Una parte final formula un llamado a la revuelta para reestructurar el mundo, por estas razones plateamos que en el poema se representa un pachakutiy $^{8}$, en el sentido en que lo ha explicado Harris y Bouysse-Cassagne: "Cuando los españoles llegaron a los Andes se produce otro pacha kuti" (1988, p. 244).

“iHatariychik”!, título del poema, en quechua es un imperativo directo: ilevántense!; en ese sentido no es una convocatoria, sino una orden. El enunciador se coloca en una posición superior y desde ese lugar reconoce la capacidad de sacudirse que poseen sus destinatarios, una imprecación para abandonar el estado en que se encuentran, porque considera que pueden transformar la realidad, este poder de remover las condiciones está en ellos, pero deben despertar la potencia de esa fuerza humillada. Precisamente otro de los verbos que se utiliza en el quechua para expresar esta capacidad transformadora es rikch'ay, despertar, abrir los ojos, ver en dos direcciones: hacia el exterior para reconocer el desastre, luego al interior para reconocer su fortaleza de abandonar el estado de quietud. Es como si al abrir los ojos ingresara el caudal ardiente de la realidad en forma perturbadora y sublevante. Entonces, hatariychik es una orden a despertar sus fuerzas para voltear el tiempo malo en el que viven: qunqurchaki, de rodillas.

El llamado del poema es a una colectividad cuyo destinatario es visibilizado en la dedicatoria: "Indiukunapaq punchawnin chayamuptin" (Para los indios cuando llegue su día” (pp. 62-63), el enunciado muestra la idea del devenir transformador. El tiempo de la escritura del poema no es el tiempo de los indios, es el tiempo de los falsos wiraquchakuna, los seres de la individualidad y la 
avaricia, este tiempo es representado en la segunda parte del poema, el advenimiento del día del indio no como una celebración cívica, sino como restitución cultural, este es el advenimiento espiralado del pasado, retorno que gesta y forja un escenario en el que se pueda expresar: "Ama kunanmanta / Qunqurchaki kawsasunchu” (en adelante no viviremos oprimidos) (pp. 70-71), es un tiempo del hatun qapariy, del gran grito, del sacudimiento, del Katatay.

El poema no está escrito para ser celebrado en este tiempo sino cuando se logre un estado mejor de vida. Por esta razón, entendemos al poema como un recorrido por los caminos de la historia del pueblo indio que va desde las formas anteriores de vida, un estado de armonía entre los hombres y la naturaleza; luego la llegada de la oscuridad, el desgarro y el dolor; finalmente, el momento del amanecer. Es en este último tramo donde recién se puede cantar y celebrar el poema, porque allí se produce el Haylli, el triunfo; es el momento en que todo se llena de intensidades "hatariychik, qapariychik, rikchakariychik, kusikuychik, kanchariychik" (Alzaos, gritad, despertad, alegraos, brillaos), de esta forma la dedicatoria se conecta con el último verso "iHaylli! iHaylli! Indiukuna” (iVictoria! iVictoria, indios!) (p. 70), solo allí aparece la palabra indio, que de alguna manera estructura un orden circular, como un retorno, un muyuy, una vuelta completa, porque antes lo designa como hallpap wawakuna, hijos de la tierra o runakuna; de esta forma envuelve la realidad verbal representada en el poema para surgir en un movimiento de liberación espiralado, donde el pasado se instala en la vena (s'irka) del presente, y en forma vibrátil lo alimenta y gira. Ello grafica una estrategia que reivindica la palabra indio, tal como enuncia una campesina: que si fue indio la palabra con que los sometieron, indio debe ser la palabra con la que se liberará (Albó, 2002). En el poema la palabra la indio se ubica en dos niveles: paratextual, en la dedicatoria y textual en el poema; de esta forma, extensionalmente abarca el texto y el contexto, el ser de papel y el ser de carne y hueso.

Ñawpa es una palabra quechua que significa lo anterior, lo remoto, lo antiguo, lo que existió en una época distante en el pasado. Precisamente la primera parte del poema se ubica en ese tiempo, el cual es visto con nostalgia, es 
el tiempo del Tawantinsuyu, tiempo del "Ñawpa pachakunapi”. Así, el primer verso muestra un anclaje temporal, que se configura como un tiempo de florecimiento y abundancia, curso natural que fue interrumpido por los falsos Wiraquchakuna. En esta primera parte es dominante la presencia de los conceptos de kuyay, kusiy, tarpuy, yanapay, de apostar por el amor, la felicidad, la siembra y solidaridad entre los hombres. Una convivencia sensible y cooperativa entre los hombres y la naturaleza, ello dentro de un universo social de plena coexistencia, lo que describe la actitud humana del trabajo como un acto de felicidad y realización colectiva. Tiempo en que se regían por los mandatos del "ama suwa, ama qilla, ama llulla".

Era el tiempo de una sociedad fundamentalmente agraria que tenía como principio el trabajo con la tierra. En ese tiempo la labor no era una obligación dolorosa que mataba, sino el trabajo hacía vivir y era un acto de felicidad, "kusilla llamkasqa” (p. 62); trabajar era vivir una alegría, y así sembraban sus terrenos: "chakranchikta tarpuspa" (p. 62), porque la siembra es un acto de esperanza, de fecundación y plantación de la felicidad, porque de ella dependía el alimento.

Un principio que guía a los runas es el ayni, que expresa la ayuda mutua entre los hombres. En el poema se representa mediante la voz quechua yanapay, la ayuda entre todos, que está presente en el verso "runa masinchiskta yanapaspa" (p. 62); es el principio de la reciprocidad, porque los hombres por igual amaban la tierra, se consideraban hijos de ella, no había un sentido de individualidad, de indiferencia sino de integración y colectividad, por ello practicar el yanapay era natural, como el ayni, ayudar a todos y recibir la ayuda de todos, uno pertenece a un ayllu y el ayllu pertenece a uno, hacer ayllu es hacer familia, hacer unidad, esta forma de trabajar les otorgaba abundancia, por ello los almacenes, los trojes, estaban llenos cada año: “pirwakunata huntaspa”(p. 62).

En cuando a los estados de ánimo, los hombres vivían con: "llampu sunqu, kusi simi”(p. 62), con un suave corazón y una palabra agradable, lo que da cuenta de la forma en que iban construyendo la felicidad, pero esta emoción no 
solo la vivían los hombres sino que transciende a la naturaleza; por ejemplo, el viento y el rocío viven esta alegría: "yakup sullanta umispa, / chiri wayrawan pukllaspa" (Con el frescor del agua confortada,/ jugando con el hálito del viento) (pp. 62-63). A ello se suma el sol, que vive feliz "Kawsaypas llamllaylla llamllaq, / Intip illanwan kusispa" (La vida henchíase de lozanía/ con el fulgor del sol alborozado) (pp. 62-63); de esta forma el sol, el agua, el viento viven esta felicidad, también están las plantas madres, o plantas dioses como la papa y el maíz: "Papa mama, sara mama”(p. 62), a ello se suman las flores multicolores como: "Waytapas pawkar sisalla" (p. 62), toda la naturaleza vive en llamllay, en lozanía. Recordemos que la papa y el maíz son plantas dioses que están presentes en los rituales del hombre del Ande, por ello no son simples vegetales los que se menciona en el poema, sino tienen un carácter sagrado como el de predecir, tal como se percibe en el poema "Kuka kintu” (pp. 28-30). Así se pueden ver los tiempos futuros y, a través de ellos, una "mama papa illa", representa a la abundancia o a hambruna, el maíz (sara), cuando es soñado, simboliza el qullqi (dinero), y la coca (Kuka) según su sabor, ya sea amargo o dulce, los tiempos malos o buenos que vendrán, de acuerdo con el dictado de su sabor.

Pero así como entre los hombres se cultiva una admirable solidaridad, también están los dioses solidarios, quienes les dan cuidado y amor: "Qapaq Inti, qulla Killa, / pachampi wiña wiñay muyuspa, / wawankunata qawaspa, / wawakunata wayllukuq (El Sol magnánimo y la Luna augusta, / eternamente recorriendo el cielo, / vigilando a sus hijos / siempre traían para ellos un halago" (pp. 62-63). El padre sol y la madre luna son los que asisten y comparten esta felicidad. El sol y la luna como dos padres tutelares recorren amorosos y vigilantes el cielo para proteger a sus hijos: los hombres y los demás seres.

Kunan es el tiempo presente, pero esta felicidad es interrumpida por la llegada de los falsos wiraquchakuna. Precisamente, es la forma en que empieza la segunda parte del poema. "Awqa runakuna chayamun" (p. 64), llegaron los enemigos del hombre, diciendo que son Wiraqucham no se parecían ni al Supay, ni al diablo, entonces surgen de una impostura, de una falsedad, vienen con una 
aparente identidad, precisamente lo primero que cuestiona el enunciador es su identidad, a la que sanciona como indefinible; no se ubican ni en lo bueno ni en lo malo, son indefinidos.

Esta parte tiene un referente histórico porque se sitúa en los funestos episodios de la conquista y la colonia, que acarrearon cambios drásticos como el mundo al revés, que se representa en Gumana Poma, evento que también se puede encontrar en otros artistas como el pintor Melchor María Mercado del que escribe Silvia Rivera Cusicanqui:

Para él, el Mundo al Revés aludía al gobierno de la república, en manos de bestias, que uncen a la gente de trabajo al arado de los bueyes [...]. Esta idea tuvo que llegarle a partir de la tradición oral, quizás basada en la noción indígena de Pachakuti, la revuelta o vuelco del espaciotiempo, con la que se inauguran largos ciclos de catástrofes o renovación de cosmos. (2016, p. 18)

Precisamente este mundo de escenarios dolorosos, trastornados, de deshumanización mediante el trabajo excesivo, es representado en este poema.

Así, los nuevos poderosos terminan transformando el mundo en que se vivía: "Mana rurasqanta, tuñichin / mana tarpusqatan, mikun, / uywanchikta tukupun, / kuyasqanchikta chiqnin, / hallpachikta suwan, / warmichikta wachun (Derrumba lo que no edificó, /come lo que no sembró, /extermina nuestro ganado, / detesta lo que amamos, / saquea nuestras tierras, / envilece a nuestras mujeres!" (pp. 64-65). Con la llegada de ellos empieza un pachakutiy una vuelta al mundo porque se trastocan todos los valores. Si antes era mundo de construcción y felicidad, ahora es de destrucción física y espiritual. Así destruyen los palacios ceremoniales sin saber el valor de la construcción ni el significado de la existencia, comen lo que no siembran, y matan a los animales si razón. De esta forma empieza con la desintegración física de una cultura por los hombres que no valoran el esfuerzo de la construcción, ni saben de lo laborioso del trabajo de la tierra, solo saben comer; tampoco saben el valor y significado de los animales, solo ponen en práctica el saqueo de las tierras: "hallpanchikta suwan", se despoja de todo. 
También desarrollan una destrucción de los valores, por ejemplo el "saqueo del ser", porque trastocan los valores. Lo que los indios amaban, como la tierra y los animales, ellos lo odian, instalando una cultura del odio y de la miseria humana. A las mujeres las volvían adulteras: "Warminchikta wachun" (p. 64). Ensucian los símbolos sagrados como "aklla wasipas qanrachasqaña” (profanado el Akllawasi) (pp. 66-67), es el inicio de la historia de sus profanaciones.

Estos con su "Awqap sunquwan" (con su corazón pervertido) (p. 64), vuelven al trabajo odioso, porque si antes el trabajo era un signo de felicidad ahora está asociado a la muerte; el trabajo se vuelve sufrimiento: "llamkaywan wañuchiwanchik"(p. 64), ahora la madre tierra se humedece con la sangre de los indios, porque ahora se ven "hallpata pukayachin" (p. 64), enrojecida por la sangre sus hijos, este es el color de la destrucción, también aparecen las lágrimas que se oponen a la felicidad anterior. Así se instala el tiempo del sufrimiento, de la sangre, de las lágrimas, y de la muerte. Pero también de la humillación, “qunqurchaki purichiwanchik" (p. 64), los hacen andar de rodillas. En este tiempo oscuro también se instala el tiempo del silencio "upallaytañam qallaykun, / sapampi, sapampi” (p. 66), se inicia el terrible tiempo de la soledad y el silencio, tiempo de ignominia.

Este desgano llega hasta las plantas; por ejemplo, los vientos arrastran sus penas entre las ramas de los árboles, contrario al tiempo anterior que está signado por el pukllay, por la fiesta, pues jugaba con los árboles, ahora es lamento. Igual ocurre con las flores que son humilladas, sus hojas se inclinan, ya no hay lozanía y se resisten a adornar los campos como en tiempos anteriores. Los hombres como los pájaros y las plantas sienten que su tiempo ha sido desterrado, porque ya no puede ser lo que son.

También se producen las profanaciones al templo del Qurikancha: “suwasqaña Qurikanchapas” (p. 66), que es el templo mayor ubicado en el Cuzco, donde se encontraban las representaciones de los dioses de todas las regiones; este es profanado luego de matar a uno de los guerreros incas que más combatió a los españoles: Rumi Ñawi (ojos de piedra). Frente a este desastre, los propios 
dioses como el dios Inti, desean morir "Intipas wañukuytañam munan” (p. 66). Todo esto se desata con la muerte del inka "Qapaq Inka wañunñam, makimpi” (p. 66), es el reinado de la muerte y del pillaje.

El pachakutiy se presenta con mayor evidencia en los siguientes versos "Hallpayuq, mana hallpayuq, / llaqtayuq, mana llaqtayuq, / tukuy imayniyuq, / mana imayuq rikukun" (p. 66). Ya no queda nada, todo se ha trastocado, se ha volteado el mundo, el que tenía ya no tiene. Es un tiempo de desconcierto e inexplicable, cuyo sinsentido alcanza a los dioses andinos; de esta forma pasan de tener todo a ser wakchakuna, hombres pobres, pero no por un descuido, por una falta de ánimo para retener sino por el cruel despojo.

Una caracterización extrema de la crueldad de los falsos wiraquchakuna es la siguiente: "Kayta qawaspa, / rumipas rumikayninwan / sinchita llakikun, / manataq Wiraquchaqa" (Viendo todo esto, / la misma piedra, con ser piedra, intensamente sufre, /pero de ningún modo el Wiracocha) (p. 68-69), con estos versos da cuenta de la sensibilidad que se aloja en la dureza de una piedra, mientras que el corazón de los falsos Wiraquchakuna no se sensibilizan. Frente a este mundo desintegrado, desastroso se opera un pachakutiy social, así el hablante lírico llama a levantarse "Kunanqa, ihatariychik! Hallpap wawankuna, / warakaychikta, waququychik, / pututuykichikta qaparichiychik, / tukuy urqukuna kuchumpi, / qaparisqaykichik uyarikunampaq" (iAhora alzaos, hijos de la tierra! / Gritad, volead vuestras hondas, / tañed, vuestros pututus, / que vuestro grito sea oído / en todos los rincones de los montes) (pp. 68-69). Una palabra que es muy frecuente en los poemas que representan el pachakutiy es hatariy, las otras son sayary, richary, qapariy, haylli, que simbolizan la idea de despertar, levantarse y triunfar. Los instrumentos son los mismos, el pututo para la convocatoria, la waraka como arma que utilizan los indios. Mediante esta lucha gestan el "Musuq punchawmi illarichkan” (p. 68), un nuevo día con brillo en los corazones.

Esto es lo que provocará el cambio donde no solo están los hombres sino también toda la naturaleza: “iRichakariychik! Llamkaq runakuna / Musuq punchawmi illarichkan, / urqukunam kununuchkan, / wayrakunam qapapachkan. 
/ Inti Killam chipipichkan, / mayukunam machasqa takikuchkan, / kusikuspa, kusikuspa” (iDespertad campesinos! / Ya está amaneciendo el nuevo día, / están bramando las montañas, / el viento ulula, / el Sol y la Luna refulgen, / los ríos cantan ebrios / de nuevo regocijo" (pp. 68-69); con todo ello voltean al pachamundo y nuevamente se siembra la alegría. Así también acaba la humillación, desaparece la tristeza, la muerte, la lágrima, y surge la satisfacción. La tierra vuelve a los que la siembran y la aman: indiukuna.

En el poema se configuran dos pachakutiy. El primeo se presenta cuando se interrumpe la vida de los runakuna, destruyen su felicidad, saquean sus tierras y su ser; esto se da cuando "Chaymantapacham qallaykun / muchuqpa yarqayllan" (Desde entonces comenzó el tormento del hambre) (pp. 66-67), porque todo se transforma "Tutayanñam punchawpas, / kawsaypas manañam kawsaychu" (Se entenebrece el día, / la vida ya no es vida) (pp. 66-67), es el tiempo de la oscuridad, de hambre, de silencio, de soledad el que se instaura con la llegada de los falsos wiraquchakuna, es el pachakutiy que conduce a la opresión. El segundo pachakutiy se gesta para restablecimiento del orden perdido, los hombres despiertan y se levantan y hacen venir a su tiempo desde el pasado, para configurar un pasado actual, todo ello se simboliza mediante el nacimiento del nuevo día, con el amanecer que trae un porvenir de felicidad.

En el poema, los dioses no son protagónicos para generar un cambio, es la voz poética quien convoca. No es un hombre enviado por los apukuna como en el caso del poema "Illimani” de Kilku Warak'a, tampoco es un hijo de los dioses como es el caso del poema "Katatay" de Arguedas donde la serpiente amaru, hija de los apukuna convoca para la transformación. Tampoco en estos versos se observa el retorno de los abuelos que vuelven para revolucionar el tiempo, como es el caso del poema “Tonqorillaña kichasqa” de Dida Aguirre (2012), aunque la voz poética hace de intermediaria, sabe de la venida de los abuelos y por ello despierta a los hombres que duermen. En este poema la voz poética es la orientadora de los cambios.

Como en casi todos los poemas donde se representa el pachakutiy en 
esta transformación no solo es el hombre quien gesta el cambio, también contribuye la naturaleza en forma decisiva, no es un escenario sino se desempeñan roles actorales. Por ejemplo, en este poema el viento y las flores muestran su alegría y tristeza según los tiempos, por lo que el forjamiento de un mundo mejor, de un allin kawsay, nunca es individual sino colectivo, además involucra a la naturaleza que vive (kawsay) plenamente como cada hombre que vive su historia de lamentos y alegrías, de humillaciones y desafíos.

No hay una presencia mítica dominante, sino el protagonismo está en los hombres. Los dioses se muestran un tanto acobardados, como siguiendo el curso de los acontecimientos; no son actores decisivos, parecen humanizarse porque sufren con la misma altura humana y no tienen capacidad de responder. Por esta razón, en el poema se delega a los hombres su capacidad de transformar, y esta se presenta solo cuando se juntan, cuando todos están unidos y despiertos es cuando retorna el valor a sus cuerpos.

Este poema es un poema-carta a los indios del futuro, tal como se escribe en su dedicatoria "Indiukunapaq punchawnin chayamuptin", para los indios cuando llegue su día; ello para los indios de carne y hueso, porque en el poema este esperado nuevo amanecer llega en la tercera parte: "Musuq punchawmi illarichkan” (está amaneciendo el nuevo día) (p. 68), o más intensamente, "Punchawniykichikmi kancharichkanña" (ya está brillando vuestro día) (p. 70). En los versos mismos se advierte la intensidad del despertar de la luz, tanto interior que estalla en alegría, como exterior que desvanece el poder oscuro que humilla.

\section{Conclusión}

El pachakutiy es una categoría que contribuye con la explicación de los textos poéticos quechua que representan momentos de transformación en diferentes campos culturales, religiosos, políticos, sociales. En el poema de Guardia Mayorga se ha observado que la naturaleza no es ajena a estos cambios, sino que tiene un rol protagónico en el desarrollo de los diversos momentos en que se presenta. También advertimos que existe un conjunto de palabras que da 
cuenta de los cambios; por ejemplo, rikchariy, qapariy, halliy, hatariy que muestran la forma en que se responde al mundo oscuro de humillaciones. Por ello, la transformación se anuncia siempre como un día resplandeciente, como un día singular donde se produce el pachakutiy, día en que las flores vuelven a adornar los campos y los vientos retoman su juego con las ramas de los árboles.

\section{Notas}

${ }^{1}$ A propósito de los múltiples significados de pacha, el Inca Garcilaso relata la siguiente anécdota: "Acaeció un día, hablando de aquel lenguaje y de las muchas y diferentes significaciones que unos mismos vocablos tienen, di por ejemplo este nombre Pacha, que, pronunciado llanamente, como suenan las letras españolas, quiere decir mundo universo, y también significa el cielo y la tierra y el infierno y cualquiera suelo. Dijo entonces el fraile: 'Pues también significa ropa de vestir y de ajuar y muebles de casa'. Yo dije: 'Es verdad, pero dígame Vuestra Paternidad ¿qué diferencia hay en la pronunciación para que signifique eso?' Díjome: 'No lo sé'. Respondíle: '¿Habiendo sido maestro en la lengua ignora esto? Pues sepa que para que signifique ajuar o ropa de vestir han de pronunciar la primera sílaba apretando los labios y rompiéndolos con el aire de la voz, de manera que suene al romperlos'. Y le mostré la pronunciación de este nombre y de otros viva voce, que de otra manera no se puede enseñar" (1985, p. 70).

${ }^{2}$ Kilku Wark'a (Andrés Alencastre Gutiérrez), tiene un largo poema dedicado a este inca: "Pacakutiq", poema recogido en su libro Taki Ruro (1964), libro que considera la continuación de su poemario Taki parwa (1955). "iAi isqun ñiqinpi unancasqa Inka / llapa qharikunamanta akllasqa qhari, / kikin Intitaytaq allin curiyasqan / kay Qusqu Pacamamaq qhari wacasqan; / qanmi kanki llapa inkakunaq illan" (iOh! Inka designado en el noveno lugar. / Hombre seleccionado entre todos los hombres, / engendrado por el mismo padre Sol, / hijo de la misma madre tierra cusqueña; / tú eres la luz de todos los incas / gobernante, innovador, revolucionario".

${ }^{3}$ Véase Heinrich Helberg Chávez quien en su libro Conocimiento intercultural. Indagaciones metodológicas (2017), explica estas tensiones: "Los conocimientos prácticos han sido claramente los relegados de la historia en La Modernidad [...]. Los conocimientos de las culturas indígenas guardan muchísimas observaciones acertadas de la naturaleza y también de regularidades y efectos de cosas que se transmiten de generación en generación como indicaciones para lograr algo o como secretos para evitar que suceda lo indeseable. Estas observaciones contienen muchas veces lo esencial del conocimiento y divergen de los conocimientos científicos solo en la forma de expresarse y de transmitirlos, mas no en el contenido [...]. Sucede entonces que el método científico se nos impone como cualitativamente mejor al ensayo y error y a la transmisión oral de los sistemas de conocimiento tradicionales" (pp. 9-17).

${ }^{4}$ Esteban Ticona Alejos (2011) señala que ello tiene que ver con las lecturas de los cambios en el vestir, tratar y pensar del Presidente boliviano, así como de sus decisiones de nombrar ministros provenientes de los sectores indígenas. A este conjunto de actitudes el autor lo llama pachakuti (p. 113).

${ }^{5}$ Todas las citas estarán referidas a esta edición. 
${ }^{6}$ Esta idea que busca la unidad entre la cabeza y corazón se vincula con los procesos de desmembramiento que sufrieron tanto Tupac Amaru en el Perú y Tupac Katari en Bolivia. Luego de despedazar su cuerpo, sus partes eran enviadas a diversos lugares para ser enterradas como una práctica de escarmiento, porque un cuerpo unido era peligroso para los poderes imperiales. O en la representación de la muerte de Atahualpa, que dibuja Guaman Poma de Ayala, donde se decapita al inka, imagen que se extiende a la colectividad, tal como explica Silvia Rivera Cusicanqui: "La sociedad indígena fue descabezada" (2016, p. 24).

${ }^{7}$ Esta escena colonial ha sido vista como una "explosión de la codicia" (Cornejo Polar, 1994, p. 43), porque los españoles estaban hambrientos de oro.

${ }^{8}$ Un artículo donde se explora con plena lucidez la representación de los cambios en otros poetas quechuas es el "Pachacutiy taki: canto y poesía en la transformación del mundo", de Martín Lienhard (1988).

\section{Referencias bibliográficas}

Aguirre García, D. (2012).Qaparikuy. Grito. Lima, Perú: Pakarina Ediciones. Albó, X. (2002). Pueblos indios en la política. La Paz, Bolivia: CIPCA. Alencastre Gutiérrez, A. (Kilku Wark'a) (1955). Taki parwa. Cusco, Perú: Garcilaso. Alencastre Gutiérrez, A. (Kilku Wark'a) (1964). Taki Ruro. Cusco: H.G. Rozas . Arguedas, J. M. (1984). Katatay. Lima, Perú: Horizonte.

Arguedas, J. M. (Trad.). (2007). Dioses y hombres de Huarochirí. Narración quechua recogida por Francisco de Ávila [i1598?]. Lima: Universidad Antonio Ruiz de Montoya.

Bertonio, L. (2006 [1612]). Vocabulario de la lengua Aymara. Arequipa, Perú: Ediciones El Lector.

Bouysse Cassagne, T. (1987). La identidad aymara. Aproximación histórica (siglos XV, siglo XVI). La Paz, Bolivia: HISBOL, IFEA.

Cornejo Polar, A. (1994). Escribir en el aire. Ensayo sobre la heterogeneidad sociocultural en las literaturas andinas. Lima, Perú: Editorial Horizonte.

Garcilaso de la Vega, I. (1985). Comentarios reales. Edición de Aurelio Miró Quesada. Lima, Perú: Biblioteca Ayacucho.

González Holguín, D. (1989 [1952]). Vocabulario de la lengua general de todo el Perú Llamada Lengua qquichua o del Inca. Lima, Perú: Universidad Nacional Mayor de San Marcos.

Guaman Poma de Ayala, F. (1993 [1915]). Nueva coronica y buen gobierno. Lima, Perú: Fondo de Cultura Económica.

Guardia Mayorga, C. (Kusi Paukar). (1975). Runa simi jarawi. Lima, Perú: s. e.

Guardia Mayorga, C. (Kusi Paukar). (2004). Runasimi harawi. Lima, Perú: Ediciones Altazor.

Harris, O. y Bouysse-Cassagne, T. (1988). Pacha: en torno al pensamiento aymara. En X. Albó (Comp), Raíces de América. El mundo aymara (pp. 217-281). Madrid, España: Alianza Editorial. 
Helberg Chávez, H. (2017). Conocimiento intercultural. Indagaciones metodológicas. Lima, Perú: FIS, SUR.

Huamán, Ó. (2017). La pervivencia de la identidad cultural como memoria del tiempo moderno en "Sonqup jaraviini, Humapa jamutaynin, Runap kutipakuynin" de Kusi Paukar. (Tesis). Universidad Nacional Mayor de San Marcos, Lima, Perú.

Lara, Jesús. (s/f). La literatura de los quechuas. Ensayo y antología. La Paz, Bolivia: G. U.M.

Lienhard, M. (1988). Pachacutiy taki: canto y poesía en la transformación del mundo, Allpanchis, 20(32), 165-195.

López-Baralt, M. (2005). Para decir al Otro. Literatura y antropología en nuestra América. Madrid, España: Iberoamericana, Vervuert.

Ossio, J. (2008). En busca del orden perdido la idea de la historia en Felipe Guaman Poma de Ayala. Lima, Perú: Fondo Editorial de la Pontificia Universidad Católica del Perú.

Rivera Cusicanqui, S. (2016). Una reflexión sobre práctica ch'ixinakax utxiwa y discursos descolonizadores. Lima, Perú: La Plaza Editores.

Ticona Alejo, E. (Comp.). (2011). Bolivia en el inicio del pachakuti. La larga lucha anticolonial de los pueblos aimara y quechua. Madrid, España: Akal. 